\title{
Uma produção que se intensifica: a educação domiciliar nas pesquisas acadêmicas
}

\section{A production that intensifies: home education in academic research Una producción que se intensifica: la educación en el hogar en la investigación académica}

MARIA CELI CHAVES VASCONCELOS

Orcid Id: http://orcid.org/0000-0002-3624-4854

Universidade do Estado do Rio de Janeiro

FABIANA FERREIRA PIMENTEL KLOH

Orcid Id: http://orcid.org/0000-0002-0690-9501

Universidade Católica de Petrópolis

\begin{abstract}
Resumo: $\mathrm{O}$ artigo tem como objetivo apresentar a análise de dissertações e teses sobre a educação domiciliar, defendidas em programas de pós-graduação brasileiros. A fonte de consulta foi o Catálogo de Teses e Dissertações da Capes e a Biblioteca Digital Brasileira de Teses e Dissertações. O corpus investigativo, composto por 35 dissertações e teses, defendidas no período de 2010 até 2019 , foi analisado a partir de uma pesquisa exploratória e bibliográfica. Entre os principais achados, destacam-se o aumento do interesse pela temática com foco na legislação pertinente, além da inserção gradual da pesquisa sobre o assunto em programas de pós-graduação, predominantemente da área de Educação e do Direito, ressaltando-se a produção de um número maior de dissertações do que de teses.
\end{abstract}

Palavras-chave: Educação domiciliar. Homeschooling. Ensino em casa. Desescolarização.

Abstract: The article aims to present the analysis of dissertations and theses on homeschooling defended in Brazilian graduate programs. The source of the consultation was the Capes Theses and Dissertations Catalog and the Brazilian Digital Library of Theses and Dissertations. The investigative corpus, composed of 35 dissertations and theses defended in the period from 2010 to 2019, was analyzed from exploratory and bibliographic research. Among the main findings, we highlight the increased interest in the subject with a focus on the relevant legislation, in addition to the gradual insertion of research on the subject in graduate programs, predominantly in the area of Education and Law, with emphasis on the production of a greater number of dissertations than theses.

Key words: Home education. Homeschooling. Teach at home. Unschooling. 
Resumen: El articulo tiene como objetivo presentar el análisis de disertaciones y tesis sobre educación en el hogar, defendidas en programas de posgrado brasileños. La fuente de consulta fue el Catálogo de Tesis y Disertaciones de Capes y la Biblioteca Digital Brasileña de Tesis y Disertaciones. El corpus de investigación, compuesto por 35 disertaciones y tesis, defendidas en el periodo 2010-2019, se analizó a partir de una investigación exploratoria y bibliográfica. Entre los principales hallazgos, destacamos el mayor interés en el tema con un enfoque en la legislación relevante, además de la inserción gradual de la investigación sobre el tema en programas de posgrado, predominantemente en el área de Educación y Derecho, destacando la producción de mayor numero de disertaciones que tesis.

Palavras-chave: Educación en el hogar. Homeschooling. Enseñanza en el hogar. Desescolarización.

\section{INTRODUÇÃO}

Antes mesmo dos acontecimentos que tornaram o ano de 2020 um marco na história da humanidade, com a pandemia de Covid-19 - que levou a Organização Mundial da Saúde (OMS) ${ }^{1}$ a declarar a necessidade de quarentena e o consequente isolamento social, a fim de conter a propagação do vírus -, o movimento pela educação em regime domiciliar já vinha ganhando fôlego. Em pouco mais de uma década, a educação domiciliar passou de tema subsumido no debate educacional à pauta de discussão envolvendo os mais diversos atores, além de educadores, incluindo intelectuais, juristas, parlamentares e o próprio poder executivo, pois o presidente do país, eleito em 2018, tinha como uma das "metas" prioritárias do seu governo, a regulamentação dessa modalidade de ensino.

Embora não se trate da mesma situação, mas de circunstâncias que se aproximaram por condições diferentes, a educação sob "regime especial domiciliar” (RIO DE JANEIRO, 2020), estabelecida pela Deliberação do Conselho Estadual de Educação do Rio de Janeiro no 376/2020 como uma das medidas do afastamento social recomendada pela OMS para restringir a disseminação da pandemia de Covid-19, colocou pais e mães confrontados à tarefa de acompanhar a escolarização dos filhos no ambiente doméstico, fazendo com que pesquisas sobre o assunto fossem acessadas pela mídia, em busca de algum tipo de orientação a essas famílias.

\footnotetext{
1 A OMS declarou, em 30 de janeiro de 2020, que o surto da doença causada pelo coronavírus (Covid-19) constitui uma Emergência de Saúde Pública de Importância Internacional - o mais alto nível de alerta da organização, conforme previsto no Regulamento Sanitário Internacional. Em 11 de março de 2020, a Covid-19 foi caracterizada pela OMS como uma pandemia, conforme site oficial https://www.paho.org/bra/.
} 
Também chamada de "homeschooling", palavra que, nos Estados Unidos da América, passou a nomear esta possibilidade de educação, a partir de seu surgimento no final dos anos de 1960 (LYMAN, 2000), a educação domiciliar vai ter, no Brasil, de forma recorrente, essa denominação incorporada nas discussões sobre a modalidade de ensino que ocorre nos espaços privados, por ter seu modelo baseado no daquele país. Contudo, Vasconcelos e Morgado (2014, p. 206) alertam para o fato de que "sua tradução, para o português, não se pode dar de forma literal", pois não significa escolarização em casa, mas sim "processos de escolaridade", que acontecem "sob a responsabilidade dos familiares e sem a interferência direta do Estado".

A transposição do modelo americano para o Brasil encontrou, entretanto, desde suas primeiras experiências neste país, por volta dos anos 2000, uma majoritária oposição dos setores educacionais, ainda que sustentada por parlamentares e apoiada por segmentos da população que já praticavam ou eram simpatizantes do homeschooling. Diante desse quadro, qualquer tentativa de regulamentação dessa prática não vislumbrava nenhuma possibilidade de ser concretizada. Há menos de uma década, o tema sequer conseguia alcançar o estágio de se manter como Projeto de Lei (PL) no Parlamento brasileiro, sem que fosse arquivado, antes de chegar perto de qualquer votação plenária. Por conseguinte, sua discussão também era suprimida e restrita a algumas Comissões do Congresso, nas quais lograva êxito em ser apreciado. Vasconcelos e Boto (2020) descrevem que o primeiro movimento parlamentar sobre o assunto ocorre em 1994, percorrendo toda a primeira década dos anos 2000 com diversos PLs sendo apresentados e todos eles padecendo do mesmo destino: o arquivamento sem qualquer possibilidade de outro encaminhamento.

Entre as principais obstaculizações imputadas a esse movimento, os argumentos contrários englobavam desde aspectos econômicos, sociais, psicológicos e, notadamente, jurídicos, além das questões educacionais de defesa incondicional da escolarização obrigatória. Os que se referiam a questões econômicas, viam na educação domiciliar uma tentativa de desescolarização atrelada às políticas neoliberais de desresponsabilização dos governos para com a educação pública (VASCONCELOS, 2017). Já na esfera jurídica, a opção pela modalidade de educar os filhos fora das instituições escolares, tratada como um direito ao exercício pleno da liberdade, de alguma forma se contrapunha ao dever de educar. A contradição entre o direito e o dever estava centrada na complexa tarefa de averiguação do cumprimento da condição de educação das crianças homeschoolers, bem como de os conhecimentos oferecidos pelas famílias, serem efetivamente mapeados e supervisionados pelo poder público, correndo-se o risco de haver crianças e adolescentes sem nenhum tipo de ensino formal. No 
campo educacional - reforçado por autores que fundamentam seus estudos em referenciais da psicologia (BECKER; GRANDO; HATTTGE, 2020; RIBEIRO, 2020) -, a maior crítica, entre tantas, refere-se à falta da socialização proporcionada pelo ambiente escolar e os danos que esse relativo "isolamento", decorrente da não participação nos grupos instituídos pelas classes escolares, poderia causar a crianças e adolescentes com um universo restrito de convivência ao longo da prática do homeschooling.

Seja pela insistência das famílias que praticavam o bomeschooling, sofrendo todas as pressões legais de uma prática proibida no Brasil, seja pela oportunidade vislumbrada pelos parlamentares, o tema voltou à pauta do Congresso em 2012, por meio do PL $\mathrm{n}^{\circ}$ 3.179, buscando mudar a Lei de Diretrizes e Bases da Educação Nacional (n $\left.n^{\circ} 9.394 / 96\right)$ para permitir a educação domiciliar e, dessa vez, tornou-se a matriz de outros tantos PLs apensos que, a par dos diversos esforços do atual governo, ainda não tiveram êxito em serem aprovados.

Todavia, esse debate atravessou um longo caminho até que chegássemos às sintéticas considerações anteriores. Arquivado no parlamento até o início da década de 2010, nos meios acadêmicos, o assunto era simplesmente silenciado, confundido com outras práticas conservadoras, ignorado e até excluído, como atestam trabalhos sobre a temática enviados para eventos científicos renomados da área, cuja resposta era, sucintamente, a de que a matéria não constava do escopo de problemáticas e de pesquisas educacionais de interesse deste campo.

Ainda que se possam encontrar alguns trabalhos acadêmicos de graduação anteriores a 2010 produzidos em universidades, no que se refere à pós-graduação, de acordo com Santos (2019), em pesquisa semelhante sobre a educação domiciliar, antes do período indicado, somente podem ser localizadas uma tese e uma dissertação que trataram do assunto.

Incitada pelo forte poder midiático que desponta sobre o tema a partir de 2010, expondo a arena de disputa entre favoráveis e opositores a essa prática, a educação domiciliar passou, naquele momento, a despertar o interesse dos meios acadêmicos. A produção científica, por sua vez, voltou-se para essa problemática e, pouco a pouco, foram surgindo pesquisas em importantes instituições de ensino superior do país, cujo foco era a educação domiciliar, a legislação, as famílias, suas motivações, as circunstâncias, as discussões sobre a viabilidade ou não dessa prática, entre outras abordagens.

Nessa perspectiva, o presente artigo tem como objetivo fazer uma revisão da literatura sobre essa produção acadêmica relativa à educação domiciliar, acompanhando a sua evolução durante a última década e demonstrando o quanto o assunto se intensificou e se aprofundou, tornando-se objeto de dissertações e teses acadêmicas. Para além do objetivo central, o estudo também se justifica à 
medida que a educação domiciliar, de acordo com Vasconcelos e Boto (2020, p. 11), "já passou por diferentes circunstâncias, entre elas, mudanças no contexto político" em que está inserida, transformando-se de uma temática restrita às minorias "com poucas chances de qualquer aceitação", a "foco principal da agenda política do governo", o que a torna um assunto urgente e necessário a ser debatido no âmbito das políticas públicas educacionais.

\section{ABORDAGEM METODOLÓGICA: UMA PESQUISA BIBLIOGRÁFICA SOBRE O TEMA}

A par do propósito do presente artigo, de identificar e examinar dissertações e teses que tratam da educação domiciliar, utilizamos em nosso estudo a abordagem metodológica relativa às investigações exploratórias, partindo de uma revisão da literatura sobre o assunto, a qual resultou em uma pesquisa qualitativa e, essencialmente, bibliográfica, que remete a um balanço das referências acerca dessa matéria e sua intensificação na última década. Para tanto, tomamos como fonte de pesquisa os bancos de dados oficiais, como o Catálogo Digital de Teses e Dissertações da Capes e da Biblioteca Digital Brasileira de Teses e Dissertações (BDTD), usando diferentes indexadores nessa busca, concentrando a investigação no recorte temporal que compreendeu os anos de 2010 até 2019.

Após uma ampla pesquisa nos bancos de dados, entre os resultados obtidos, que constituem o corpus documental do estudo, foi possível localizar e acessar 35 trabalhos de mestrado e doutorado, sendo 25 dissertações e 10 teses, que enfocam a discussão a respeito da educação domiciliar. Nota-se, portanto, a priori, um aumento gradual do interesse pelo assunto, a julgar pelo número de trabalhos acadêmicos que assinala dois registros nos primeiros anos da década, ampliandose para até sete registros localizados em 2016. Essa constatação corroborou a hipótese inicial da pesquisa, de haver uma intensificação do interesse pelo tema em programas de pós-graduação de universidades brasileiras, justificando o recorte temporal adotado.

Cabe ressaltar, entretanto, que, por se tratar de uma pesquisa qualitativa, exclusivamente bibliográfica, cujo objetivo é demonstrar a intensificação e o foco de estudos sobre a temática em pauta, os dados numéricos não são absolutos, pois dependem das variáveis da disponibilidade dos bancos de teses e dissertações, bem como dos indexadores utilizados que nem sempre correspondem àqueles usados na área de educação. Quanto a esse último aspecto, vale notar que nossa pesquisa abrange a revisão da literatura de trabalhos acadêmicos produzidos na área de Ciências Humanas e Sociais, podendo haver outras abordagens em áreas distintas. 
De toda forma, pelos motivos elencados, o conjunto analisado não tem nenhuma pretensão de ser absoluto, mas tão somente constituir-se em um exemplo da intensificação da produção acadêmica sobre a temática, certamente, havendo outros tantos trabalhos não disponíveis ou não localizados nos bancos de dissertações e teses consultados, o que comprova a proposição que afirmamos neste artigo.

Nossa busca pelos trabalhos acadêmicos nos bancos de dissertações e teses, no intervalo selecionado de 2010 a 2019, iniciou pelas palavras-chave utilizadas como indexadores, o que nos levou a perceber que nem sempre a "chave" para a temática pode se restringir às palavras indexadas, uma vez que o tema em pauta, a educação domiciliar, em que pese já possuir muitas generalizações em sua acumulação teórica, ainda possui especificidades de tratamento em cada área de inserção.

Após uma seleção muito mais ampla, nossa eleição chegou às seguintes palavras-chaves: educação domiciliar, homeschooling, ensino em casa e desescolarização. As palavras-chaves educação doméstica e ensino no lar somente foram encontradas em dissertações e teses referentes a essa prática no século XIX ou no início do século XX, bastante marcadas por essa datação temporal e relacionadas às práticas de "educação na casa"² (VASCONCELOS, 2005), usadas para ensinar crianças e adolescentes na esfera privada, sem a interferência do estado, antes da obrigatoriedade escolar ser decretada e, antes ainda, da hegemonia da escola ter destituído a casa como um lugar aceito para escolarização (VASCONCELOS; MORGADO, 2014).

Dessa forma, com base nas palavras-chaves, educação domiciliar, homeschooling, ensino em casa e desescolarização, e considerando a sua incidência, elegemos essas quatro categorias para a classificação dos trabalhos acadêmicos encontrados e sua posterior análise. Após concluído o levantamento nos bancos de dados consultados, o instrumento analítico metodológico adotado abarcou, respectivamente, aspectos relativos à intensificação da produção acadêmica, a natureza dos programas de pós-graduação dos quais se originou o estudo, a tipologia dos trabalhos, distribuídos entre dissertações e teses, e as principais problemáticas das pesquisas levantadas. Quanto a esse último aspecto do escopo analítico, optamos por examinar mais detalhadamente as teses de doutorado sobre o tema, tendo em vista constituírem-se estudos mais aprofundados, buscando apresentar uma síntese das pesquisas realizadas.

2 A terminologia "educação na casa" refere-se à sua equiparação/inversão à "educação na escola", cuja subjetividade é diferente da abrangida por "educação em casa", ou seja, essa prática é exposta como educação formal realizada na própria casa do aluno (VASCONCELOS, 2017). 


\section{É PRECISO FALAR DO ASSUNTO: O QUE TEM DITO A PRODUÇÃO ACADÊMICA?}

No que se refere aos termos educação domiciliar, homeschooling, ensino em casa e desescolarização, constata-se uma produção acadêmica que vem se intensificando com o passar dos anos, interessando, particularmente, a pesquisadores das áreas da Educação e do Direito. Para a visualização de como essa produção tem se movimentado em relação não só a quantidade, mas também ao seu interesse por programas de pós-graduação com expertise em políticas educacionais, elaboramos dois quadros demonstrativos. Para sua elaboração, utilizamos como critério a ordenação cronológica, iniciando pelos trabalhos mais recentes, com o objetivo de acompanhar a evolução da temática, no que diz respeito à ampliação e ao aprofundamento dos estudos.

$O$ Quadro 1 apresenta os trabalhos relacionados às palavras-chaves educação domiciliar e homeschooling, visto que, algumas vezes, elas aparecem juntas ou são usadas como sinônimas nos textos acadêmicos, dificultando, sobremaneira, separá-las em categorizações diferenciadas. Contudo, optamos em separá-las em duas categorias, verificando a priorização do autor por uma ou outra, no título, indexadores e resumo, e computando a frequência em que aparecia nesses três campos.

\section{Quadro 1 - Termo de busca: educação domiciliar e homeschooling - dissertações (D) e teses (T) por título, autor, instituição e ano - de 2019 a 2010}

\begin{tabular}{|c|c|c|c|c|}
\hline$\underset{\text { conous }}{\operatorname{monsen}}$ & Nivel e Programa & TítuLo & AUTOR & $\begin{array}{l}\text { INSTITUIÇĀO } \\
\text { (DATA) }\end{array}$ \\
\hline \multirow{8}{*}{ 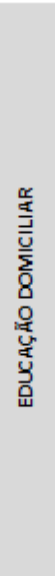 } & $\begin{array}{l}\text { Mestrado em } \\
\text { Educação (D) }\end{array}$ & $\begin{array}{c}\text { Educação domiciliar ou "lugar de criança é na escola"?: uma } \\
\text { análise sobre a proposta de homeschooling no Brasil }\end{array}$ & $\begin{array}{l}\text { Aline Lyra dos } \\
\text { Santos }\end{array}$ & $\begin{array}{l}\text { Universidade Federal do } \\
\text { Rio de Janeiro (2019) }\end{array}$ \\
\hline & $\begin{array}{l}\text { Mestrado em } \\
\text { Educação (D) }\end{array}$ & $\begin{array}{l}\text { Práticas pedagógicas na educação domiciliar: um estudo de } \\
\text { caso em Aracaju/SE }\end{array}$ & $\begin{array}{l}\text { Alexsandro Vieira } \\
\text { Pessoa }\end{array}$ & $\begin{array}{c}\text { Universidade Federal de } \\
\text { Sergipe (2019) }\end{array}$ \\
\hline & $\begin{array}{l}\text { Mestrado em } \\
\text { Direitos } \\
\text { Fundamentais (D) }\end{array}$ & $\begin{array}{l}\text { Ensino domiciliar como direito-dever fundamental à } \\
\text { educação: conformação deôntico-axiológica dos seus } \\
\text { aspectos normativos e principiológicos }\end{array}$ & $\begin{array}{c}\text { Claudio Márcio } \\
\text { Bernardes }\end{array}$ & $\begin{array}{l}\text { Universidade de Itaúna } \\
\qquad(2017)\end{array}$ \\
\hline & $\begin{array}{l}\text { Doutorado em } \\
\text { Educação Escolar (T) }\end{array}$ & $\begin{array}{c}\text { Além da escola: reflexões teórico-metodológicas com base na } \\
\text { análise de práticas educativas alternativas descobertas em } \\
\text { áreas rurais da região de São Carlos, SP }\end{array}$ & $\begin{array}{l}\text { Marinaldo } \\
\text { Fernando de } \\
\text { Souza }\end{array}$ & $\begin{array}{l}\text { Universidade Estadual } \\
\text { Paulista (2016) }\end{array}$ \\
\hline & $\begin{array}{l}\text { Mestrado em } \\
\quad \text { Direito } \\
\text { Constitucional (D) }\end{array}$ & O direito de optar pela educação domiciliar no Brasil & $\begin{array}{l}\text { Nardejane } \\
\text { Martins Cardoso }\end{array}$ & $\begin{array}{l}\text { Universidade de } \\
\text { Fortaleza (2016) }\end{array}$ \\
\hline & $\begin{array}{l}\text { Mestrado em } \\
\text { Direito (D) }\end{array}$ & $\begin{array}{l}\text { Educação institucionalizada: serviço público inafastável } \\
\text { enquanto expressão dos valores comunitários adotados } \\
\text { democraticamente }\end{array}$ & Aline Eliana Busch & $\begin{array}{l}\text { Universidade de Santa } \\
\text { Cruz do Sul (2014) }\end{array}$ \\
\hline & $\begin{array}{l}\text { Mestrado em } \\
\text { Educação (D) }\end{array}$ & $\begin{array}{l}\text { Homeschooling no Brasil: a legislação, os projetos de lei e as } \\
\text { decisões judiciais }\end{array}$ & $\begin{array}{l}\text { Fabiana Ferreira } \\
\text { Pimentel Kloh }\end{array}$ & $\begin{array}{l}\text { Universidade Católica de } \\
\text { Petrópolis (2014) }\end{array}$ \\
\hline & $\begin{array}{l}\text { Mestrado em } \\
\text { Ciências Jurídicas (D) }\end{array}$ & $\begin{array}{l}\text { Obrigatorie dade escolar à luz dos objetivos constitucionais do } \\
\text { direito à educação: análise da educação domiciliar }\end{array}$ & Tatiana Richetti & $\begin{array}{c}\text { Centro Universitário de } \\
\text { Maringá (2014) }\end{array}$ \\
\hline
\end{tabular}




\section{Quadro 1 - Termo de busca: educação domiciliar e homeschooling - dissertações (D) e teses (T) por título, autor, instituição e ano - de 2019 a 2010}

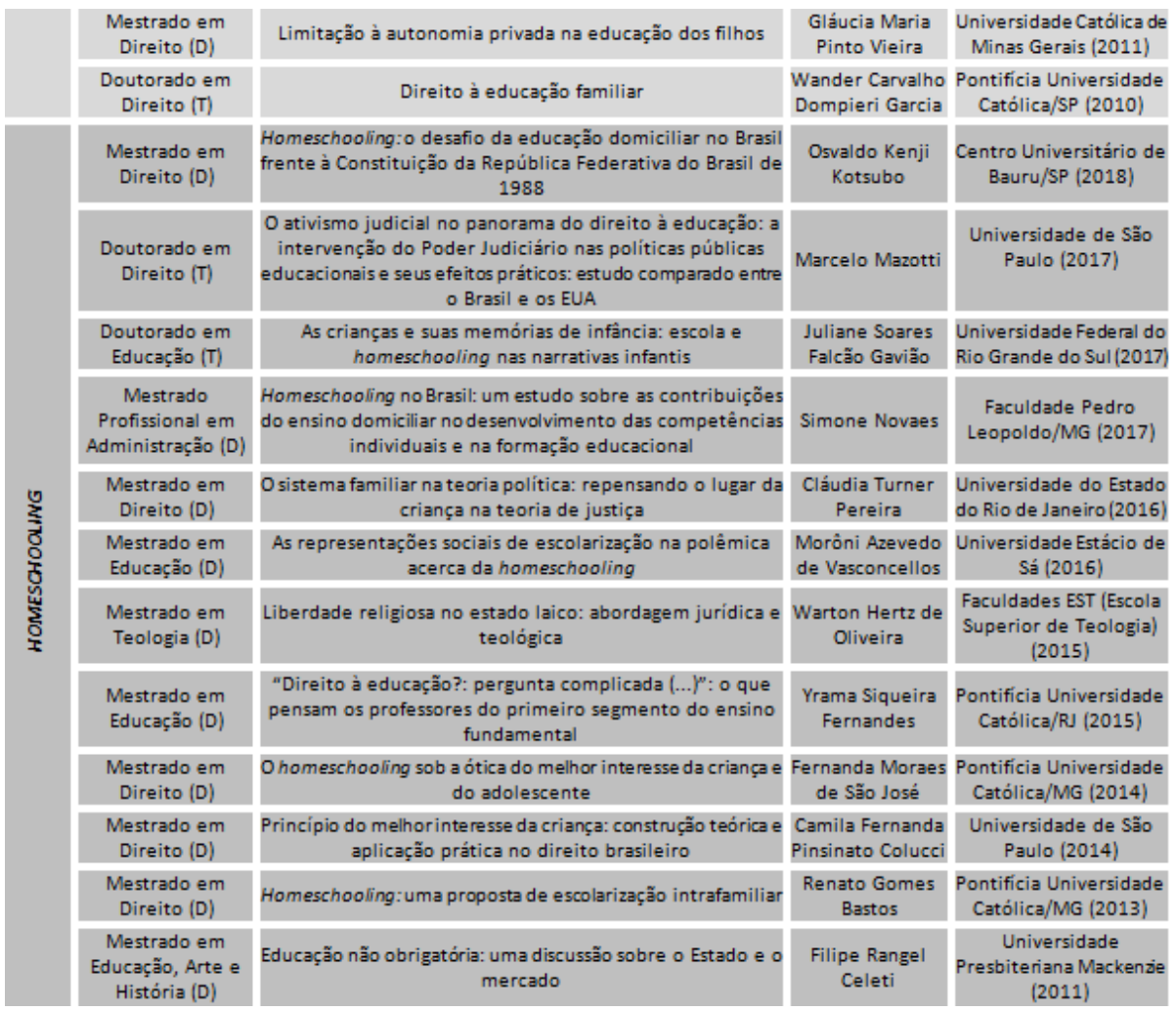

Fonte: Elaborado pelas autoras.

Entre os 22 trabalhos acadêmicos listados no Quadro 1, consta-se uma equivalência da produção em programas de pós-graduação em Direito, seguidos pelos de Educação. Além disso, o assunto é mais abordado em dissertações de mestrado (18 trabalhos) do que em teses de doutorado (4 resultados), devendo se considerar, porém, o próprio volume existente de cada uma dessas produções.

Completando nossa categorização, apresentamos as demais produções relacionadas às palavras-chave ensino em casa e desescolarização, dispostas no Quadro 2. Vale notar que os trabalhos acadêmicos agrupados nessas categorias também se relacionam à educação domiciliar ou ao homeschooling, mas sua classificação em outro indexador deve-se à forma como o próprio autor encaminha a apresentação de seu tema. Além disso, alguns desses trabalhos, especialmente na categoria que denominamos de ensino em casa, fogem a um único enfoque, 
aproximando a legislação de práticas educativas observadas ou debatendo a questão sob aspectos jurídicos, etnográficos, psicológicos e até filosóficos. Assinala-se, ainda, que não foram encontrados trabalhos com os termos de busca ensino em casa e desescolarização nos anos de 2010 e 2011.

\section{Quadro 2 - Termo de busca: ensino em casa e desescolarização - dissertações (D) e teses (T) por título, autor, instituição e ano - de 2019 a 2012}

\begin{tabular}{|c|c|c|c|c|}
\hline $\operatorname{monses}_{\text {comis }}$ & Nivel e Programa & Tituio & AUTOR & $\begin{array}{l}\text { INSTITUIÇĀO } \\
\text { (DATA) }\end{array}$ \\
\hline \multirow{4}{*}{ 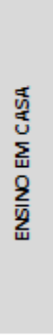 } & $\begin{array}{l}\text { Mestrado em } \\
\text { Educação (D) }\end{array}$ & $\begin{array}{c}\text { Mamãe é a melhor professora!: uma etnografia } \\
\text { junto a três familias que educam suas crianças fora } \\
\text { da escola }\end{array}$ & $\begin{array}{l}\text { Gabriela Braga } \\
\text { Loreti }\end{array}$ & $\begin{array}{l}\text { Universidade Federal de } \\
\text { São Carlos/SP (2019) }\end{array}$ \\
\hline & $\begin{array}{l}\text { Mestrado em } \\
\text { Memória, } \\
\text { Linguagem e } \\
\text { Sociedade (D) }\end{array}$ & $\begin{array}{c}\text { Ensino em casa no Brasil: um estudo com base na } \\
\text { memória social acerca da obrigatoriedade e } \\
\text { liberdade de ensino nas constituições brasileiras e } \\
\text { em demandas jurídicas recentes }\end{array}$ & $\begin{array}{l}\text { Ivana Bittencourt } \\
\text { Lima }\end{array}$ & $\begin{array}{l}\text { Universidade Estadual } \\
\text { do Sudoeste da Bahia } \\
\qquad(2015)\end{array}$ \\
\hline & $\begin{array}{l}\text { Doutorado em } \\
\text { Educação (T) }\end{array}$ & Ensino em casa no Brasil: um desafio à escola? & $\begin{array}{l}\text { Luciane Muniz } \\
\text { Ribeiro Barbosa }\end{array}$ & $\begin{array}{l}\text { Universidade de São } \\
\quad \text { Paulo (2013) }\end{array}$ \\
\hline & $\begin{array}{l}\text { Doutorado em } \\
\text { Direito }(T)\end{array}$ & $\begin{array}{l}\text { Intervenção estatal no exercício da autoridade } \\
\text { familiar }\end{array}$ & $\begin{array}{l}\text { Ana Paula Corrêa } \\
\text { Patiño }\end{array}$ & $\begin{array}{l}\text { Universidade de São } \\
\text { Paulo (2012) }\end{array}$ \\
\hline \multirow{9}{*}{ 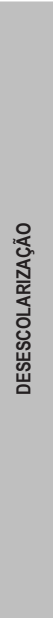 } & $\begin{array}{l}\text { Doutorado em } \\
\text { Educação (T) }\end{array}$ & Educação "alternativa": do discurso à imagem & $\begin{array}{l}\text { Gabriele Nigra } \\
\text { Salgado }\end{array}$ & $\begin{array}{l}\text { Universidade Federal de } \\
\text { Santa Catarina (2018) }\end{array}$ \\
\hline & $\begin{array}{l}\text { Mestrado em } \\
\text { Psicologia (D) }\end{array}$ & $\begin{array}{l}\text { Dever de escola ou direito de escolha: uma análise } \\
\text { da compulsoriedade escolar }\end{array}$ & $\begin{array}{l}\text { Luis Eduardo } \\
\text { Oliveira Alejarra }\end{array}$ & $\begin{array}{c}\text { Centro Universitário de } \\
\text { Brasilia (2017) }\end{array}$ \\
\hline & $\begin{array}{l}\text { Mestrado } \\
\text { Profissional em } \\
\text { Ensino de Física (D) }\end{array}$ & $\begin{array}{c}\text { Teias de aprendizagem: uma proposta de ensino com } \\
\text { recursos educacionais abertos baseada na } \\
\text { perspectiva de Ivan Illich }\end{array}$ & Ismael de Lima & $\begin{array}{l}\text { Universidade Federal do } \\
\text { Rio Grande do Sul (2017) }\end{array}$ \\
\hline & $\begin{array}{l}\text { Doutorado em } \\
\text { Filosofia (T) }\end{array}$ & $\begin{array}{c}\text { Ontologia gestáltica: um ensaio sobre a teoria da } \\
\text { experiência de Paul Goodman }\end{array}$ & $\begin{array}{l}\text { Marcus Cézar de } \\
\text { Borba Belmino }\end{array}$ & $\begin{array}{l}\text { Universidade Federal de } \\
\text { Santa Catarina (2016) }\end{array}$ \\
\hline & $\begin{array}{l}\text { Mestrado em } \\
\text { Psicologia Escolar } \\
\text { (D) }\end{array}$ & $\begin{array}{c}\text { Práticas educacionais e processos de subjetivação } \\
\text { em meio a propostas de desescolarizaçãa: tensões, } \\
\text { potências e perigos }\end{array}$ & $\begin{array}{l}\text { Marcela Peters } \\
\text { Cremaso } \\
\text { Gonçalves }\end{array}$ & $\begin{array}{l}\text { Universidade de São } \\
\text { Paulo (2016) }\end{array}$ \\
\hline & $\begin{array}{l}\text { Doutorado em } \\
\text { Educação }(T)\end{array}$ & $\begin{array}{l}\text { Ajuste estrutural do capital: alicerce da } \\
\text { desconstrução da escola pública estatal }\end{array}$ & $\begin{array}{l}\text { Lêda Vasconcelos } \\
\text { Carvalho }\end{array}$ & $\begin{array}{l}\text { Universidade Federal do } \\
\text { Ceará (2016) }\end{array}$ \\
\hline & $\begin{array}{l}\text { Doutorado em } \\
\text { Educação (T) }\end{array}$ & $\begin{array}{l}\text { A educação familiar desescolarizada como um direito } \\
\text { da criança e do adolescente: relevância, limites e } \\
\text { possibilidades na ampliação do direito à educação }\end{array}$ & $\begin{array}{l}\text { Édison Prado de } \\
\text { Andrade }\end{array}$ & $\begin{array}{l}\text { Universidade de São } \\
\quad \text { Paulo (2014) }\end{array}$ \\
\hline & $\begin{array}{l}\text { Mestrado em } \\
\text { Educação (D) }\end{array}$ & Para onde caminham as escolas? & $\begin{array}{l}\text { Gabriela Freitas } \\
\text { de Almeida }\end{array}$ & $\begin{array}{l}\text { Universidade de Brasília } \\
\qquad(2014)\end{array}$ \\
\hline & $\begin{array}{l}\text { Mestrado em } \\
\text { Educação (D) }\end{array}$ & $\begin{array}{l}\text { O abolicionismo escolar: reflexões a partir do } \\
\text { adoecimento e da deserção dos professores }\end{array}$ & $\begin{array}{l}\text { Danilo Alexandre } \\
\text { Ferreira Camargo }\end{array}$ & $\begin{array}{l}\text { Universidade de São } \\
\text { Paulo (2012) }\end{array}$ \\
\hline
\end{tabular}

Fonte: Elaborado pelas autoras.

No Quadro 2, já se observa uma equivalência entre dissertações e teses, com sete pesquisas de mestrado e seis de doutorado. Isso pode ocorrer pela utilização de termos de busca mais específicos. No entanto, cabe ressaltar que os quadros 1 e 2 não totalizam toda a produção acadêmica sobre o tema nos anos de 2010 a 2019, mas apenas aquela possível de ser localizada por meio dos indexadores nos bancos de dissertações e teses já referidos. 
Ainda que os programas de pós-graduação em Direito e, predominantemente, os de Educação estejam presentes nos 13 trabalhos acadêmicos distribuídos nas duas categorias elencadas no Quadro 2, percebe-se, em ambos os quadros apresentados, a existência de produção científica oriunda de outros programas tão diversos quanto os de Administração, Educação Física e de Memória, Linguagem e Sociedade.

Em que pese o tempo necessário para elaboração de uma dissertação de mestrado e de, no mínimo, quatro anos, para uma tese de doutorado, verifica-se que a produção acadêmica sobre o assunto tem um aumento considerável entre os anos de 2014 a 2019, provavelmente estimulada pela exposição midiática do tema, mas também pelos projetos de lei que buscavam sua regulamentação. Outro aspecto que gerou expectativa e ampliou o debate e a produção em torno da questão da educação domiciliar foi a chegada ao Supremo Tribunal Federal, em 15 de outubro de 2013, do "Recurso Extraordinário com Agravo", que tratava do caso de uma criança do Rio Grande do Sul, que solicitava o direito de estudar em casa "pelo sistema conhecido como "bomeschooling" (VASCONCELOS; BOTO, 2020, p. 13).

A partir da possibilidade real de sua regulamentação, seja pela via do poder legislativo, porém ainda mais iminente, de sua autorização pela via do poder judiciário - embora o julgamento do processo só tenha ocorrido em 2018, provocando um posicionamento da Suprema Corte brasileira -, fez com que a problemática da permissão da educação domiciliar passasse a ser um tema de investigação sob distintas perspectivas, englobando o direito, a educação e a psicologia, além de inúmeras outras proposições sobre a matéria.

Contudo, ainda que essa produção tenha sido ampliada e que o assunto tenha sido aceito nos programas de pós-graduação com a legitimidade necessária para ser discutido, sua abordagem é ainda pequena diante de outros temas já consolidados e pesquisados recorrentemente. Tal fato pode se dever também a essa ser uma questão que diz respeito a um grupo minoritário, cuja reivindicação atinge uma parcela bastante limitada da sociedade. Entretanto, a mudança que a sua regulamentação pode acarretar traz consequências sobre todos os sistemas de ensino, sendo a primeira vez, desde que planejada ou decretada a frequência à escolaridade obrigatória nas sucessivas Constituições do século XX, que haveria a possibilidade de uma educação legítima fora do ambiente escolar. Ainda assim, mesmo com a intensificação da produção acadêmica observada nos quadros $1 \mathrm{e}$ 2 , pode-se afirmar que o tema tem sido pouco pesquisado quando comparado a outras temáticas também relacionadas a minorias e educação. 
Além disso, observa-se que as temáticas pesquisadas relativas às quatro categorias (educação domiciliar, homeschooling, ensino em casa e desescolarização) são majoritariamente voltadas para a questão da regulamentação, normatização e discussão da legislação em suas possibilidades de permissão, acenando para o confronto entre "casa e escola", além de debaterem a obrigatoriedade do sistema escolar. Das 35 pesquisas levantadas, 17 estão neste grupo. A essas pesquisas, que têm como objeto a legislação e a discussão sobre o direito das famílias versus o dever do Estado, seguem oito investigações que se debruçam sobre as motivações de famílias e de crianças para a prática do homeschooling, apontando para circunstâncias religiosas, psicológicas, alternativas, etc. Nesse segundo grupo, também se encontram os trabalhos acadêmicos da área do Direito que tratam da temática como o princípio do "melhor interesse da criança", nos quais são examinados os interesses e argumentos das famílias.

Em um terceiro grupo, ainda pouco abrangente, no qual localizamos apenas quatro pesquisas, estão os trabalhos que têm como foco práticas de educação domiciliar, realizadas por determinada família ou comunidade, com estudos de caso ou etnografias que, no entanto, também fazem uma longa introdução relativa à legislação e às suas intercorrências no país. Reunidas em um quarto grupo, com semelhante argumentação inicial, mas com perspectivas diferentes, duas pesquisas elencadas na categoria desescolarização abordam o pensamento teórico de ensaístas dessa ideia, como Ivan Illich e Paul Goodman, e as tensões dessas ideologias na sociedade atual. Em um quinto agrupamento estão dois trabalhos que tratam da questão sob o aspecto econômico, confrontando Estado, capital e mercado e, finalizando, uma sexta possibilidade de aproximação entre dois trabalhos que remetem à questão da educação domiciliar sob a ótica dos professores.

Como se verifica na síntese analítica sobre o foco das pesquisas que envolvem a educação domiciliar, o tema ainda carece de ampliação e aprofundamento. Assim como são poucas as pesquisas sobre o assunto, também são extremamente limitadas as problemáticas oriundas de sua intervenção. São inúmeras as possibilidades de temáticas que ainda necessitam do olhar de pesquisadores. Entre as questões deflagradoras de projetos de pesquisa a serem desenvolvidos sobre a educação domiciliar, para além dos conflitos e das clivagens relativas à permissão, destacam-se, por exemplo, estudos sobre a educação de filhos de velejadores e membros de expedições que permanecem acompanhando a família em viagens, de filhos de trabalhadores enviados para países de língua e alfabeto bastante diferenciado por um curto período de tempo, de filhos de artistas que se movimentam com suas companhias pelo interior do país, enfim, distintas possibilidades que também abarcam fontes diversas. Os estudos também poderiam 
enfocar a temática a partir da imprensa, das diferentes realidades mundiais, da política, da economia, da psicologia, da religião, dos modos de vida alternativos, da liberdade e de suas limitações diante do Estado, entre outros infinitos objetos que podem ser pensados para investigação, excedendo as recorrentes discussões sobre a legislação, o direito e a obrigatoriedade escolar.

Com base nas produções listadas nos quadros 1 e 2 , selecionamos alguns trabalhos de cada uma das quatro categorias para serem analisados mais detalhadamente, tendo como critério a aderência entre a temática descrita pelo pesquisador e a palavra-chave categorizada nos respectivos quadros. Quanto mais afeito o texto acadêmico ao indexador, maior interesse despertou para a nossa análise. Cabe ressaltar que, tendo em vista as limitações textuais, priorizamos as teses de doutorado, considerando o aprofundamento exigido, embora a pesquisa realizada contenha a revisão de toda a produção elencada (KLOH, 2020). Nessa perspectiva, foram revisadas 10 teses, sendo seis defendidas em programas de pós-graduação em Educação, três em programas de pós-graduação em Direito e uma em programa de pós-graduação em Filosofia.

Assim, tomando a categoria que consideramos a mais abrangente para o assunto, ou seja, a educação domiciliar, um dos primeiros trabalhos anotados no início da década de 2010 é o de Wander Carvalho Dompieri Garcia, intitulado "Direito à educação familiar", realizado no curso de doutorado em Direito da Pontifícia Universidade Católica de São Paulo (2010). Em uma abordagem predominantemente jurídica, o autor analisa os contornos do direito à educação familiar, tendo percebido que, até então, esse enfoque, apesar de relevante, ainda era pouco explorado no âmbito do Direito. Parte de sua tese foi dedicada a identificar as sanções jurídicas destinadas a promover eficácia das disposições constitucionais pertinentes ao direito à educação familiar. Após analisar a educação familiar sob fundamentos filosóficos, psicológicos e jurídicos, Garcia (2010) conclui que a melhor instituição para instruir os pais em como realizar a educação familiar seria a própria escola. O autor compreende a educação familiar como um direito, mas devendo ser exercida em comunhão de esforços com a escola e, preferencialmente, no contexto das práticas e do ambiente escolar.

Ana Paula Corrêa Patiño, na tese de doutorado denominada "Intervenção estatal no exercício da autoridade familiar” (2012) também realizada na área de Direito, pela Universidade de São Paulo, buscou analisar a intervenção estatal no exercício da autoridade familiar. Patiño (2012) discute o fato de o Estado impor aos pais a autoridade familiar, delegando a responsabilidade de criar e educar os filhos, ao passo que lhes retira a liberdade de exercer essa autoridade com autonomia. A autora alega que a intervenção, embora necessária, se excessivamente exercida, torna-se ilegítima. Ela apresenta, ainda, alguns exemplos de intervenção indevida 
do Estado nas relações familiares e, entre esses exemplos, está a obrigatoriedade de matricular os filhos no ensino fundamental, submetendo-os à educação formal, impedindo que os pais ofereçam educação doméstica. Para essa autora, a educação domiciliar deveria ser garantida, tendo em vista que o dever de educar consiste em direito de os pais educarem os filhos, de acordo com as próprias convicções.

$\mathrm{Na}$ mesma categoria de ensino em casa, também como tese de doutorado, mas no programa de pós-graduação em Educação da Universidade de São Paulo, o primeiro trabalho acadêmico específico sobre o assunto no campo educacional e que surge como referência em sua área, é o de Luciane Muniz Ribeiro Barbosa, denominado "Ensino em casa no Brasil: um desafio à escola?" (2013). Nele, a autora analisa os princípios e fundamentos do ensino em casa e as possibilidades de normatização no Brasil, para atender ao crescente número de famílias brasileiras que optam por ensinar seus filhos em casa, ao invés de enviá-los à escola. A tese de Barbosa (2013), embora verifique que o ensino em casa tem sido um movimento que se amplia, demonstra que se trata de um fenômeno de "expansão silenciosa e pouco analisado" (p. 285), desafiando a necessidade de uma análise mais profunda. Uma das constatações da autora é que "a visão majoritária é a de que o direito à educação pressupõe a frequência à instituição escolar" (p. 292293), porém essa visão está longe de ser unânime. Barbosa (2013) reconhece como "aceitável a posição a favor da normatização" da educação domiciliar, tendo em vista a existência da possibilidade de escolha pelo ensino privado. Contudo, defende que se concentrem esforços e recursos estatais e sociais, optando por relevante e urgente "reforma no sistema educacional, especialmente o público" (BARBOSA, 2013, p. 309).

Igualmente em programa de pós-graduação em Educação da Universidade de São Paulo, Édison Prado de Andrade, em uma tese de doutorado que reúne Pedagogia e Direito, cujo título é "A educação familiar desescolarizada como um direito da criança e do adolescente: relevância, limites e possibilidades na ampliação do direito à educação" (2014), analisa o movimento social que visa garantir a realização de uma educação de crianças e adolescentes de modo desescolarizado. Nela, o autor reflete sobre os marcos constitucionais e legais, bem como sobre a doutrina e a jurisprudência acerca do direito à educação, demonstrando que a educação familiar desescolarizada está de acordo com a previsão constitucional, não havendo, por essa razão, motivos fundamentados para que seja proibida no Brasil. A proposta de Andrade (2014) com sua pesquisa é ampliar a visibilidade das teses que corroboram o direito a uma educação fora do monopólio escolar, aproximando-se, assim, do que Barbosa (2013) afirmou quanto a estar longe de ser unânime a questão da (in)constitucionalidade da educação na casa no Brasil. 
Já em uma outra perspectiva, por se tratar de um programa de pósgraduação em Filosofia, a tese de doutorado de Marcus Cézar de Borba Belmino, defendida na Universidade Federal de Santa Catarina, é intitulada "Ontologia gestáltica: um ensaio sobre a teoria da experiência em Paul Goodman (2016)". Tratando da acepção filosófica do fenômeno da educação domiciliar, com base na teoria anarquista de Paul Goodman, ainda que este não tenha sido o foco central do seu estudo, mas apenas uma das vertentes para compreensão da ontologia gestáltica, o autor problematiza o papel da escola como instrumento de domesticação. Segundo Belmino (2016), Goodman, um dos pilares do movimento anarquista, foi um ferrenho crítico aos modelos de educação tradicional, um dos principais nomes da desescolarização e um ativista do movimento contra a escolarização obrigatória. A pesquisa de Belmino (2016) apurou que Goodman, ao contrário de Ivan Illich, não era contra o sistema escolar, porém apostava numa reforma profunda das escolas para que gerassem efetivamente o "desenvolvimento humano". Segundo Goodman, o problema estava na obrigatoriedade do ensino por ser diretamente ligado às "demandas do sistema organizado e não com as reais demandas de uma determinada comunidade" (BELMINO, 2016, p. 334). Em sua tese, o autor propõe reflexões sobre o processo de escolarização, conforme o entendimento de Goodman, que seriam: "não ter 'escola alguma' para algumas classes"; flexibilizar o espaço físico da escola, de forma que se utilize "a cidade mesma como se fosse uma escola"; e "o comparecimento às aulas não seja obrigatório” (BELMINO, 2016, p. 335-337).

Em uma análise mais macroestrutural, voltada para as políticas públicas educacionais, está a tese de doutorado de Lêda Vasconcelos Carvalho, defendida no programa de pós-graduação em Educação da Universidade Federal do Ceará, intitulada "Ajuste estrutural do capital: alicerce da desconstrução da escola pública estatal" (2016). Nela, a autora aproxima-se do tema da desescolarização, analisando a vinculação entre educação e processo produtivo e, particularmente, entre educação e políticas de desenvolvimento econômico, tendo como resultado a subordinação das atividades educativas/formativas à lógica do sistema de produção. A tese se insere em um cenário de aprofundamento da crise mundial do sistema capitalista produtor de mercadorias, no qual as medidas tomadas em relação à população trabalhadora do mundo inteiro, mitiga os direitos sociais e democráticos que foram conquistados pela força da luta de classes se instituindo como "normatividades jurídicas nacionais". Carvalho (2016) analisa como as políticas decorrentes do sistema capitalista atuam sobre a educação, especialmente, a educação pública, em um contexto histórico de negação do primado da universalidade e igualdade de direitos, de desconstrução dos direitos 
sociais e democráticos, decorrentes dos desdobramentos do capital internacional e, nessa ofensiva, na reanimação dos postulados "teóricos" dos homens da "desescolarização da sociedade".

Também como tese de doutorado, em programa de pós-graduação em Educação Escolar da Universidade Estadual Paulista, Marinaldo Fernando de Souza apresenta sua pesquisa intitulada: "Além da escola: reflexões teóricometodológicas com base na análise de práticas educativas alternativas descobertas em áreas rurais da região de São Carlos SP” (2016). O objetivo central foi de estudar práticas educativas alternativas que se aproximavam da educação domiciliar, em territórios rurais da região de São Carlos-SP. O autor relata as escolhas de um casal pela vida em comunidade, também vislumbrando a possibilidade de realizar a educação dos próprios filhos dentro de uma perspectiva de educação domiciliar. A partir de uma pesquisa etnográfica, Souza (2016, p. 90) evidencia a narrativa de que "o ideal de desescolarização da educação, é uma proposta ousada que está vinculada ao desejo anarquista de uma educação (ou uma escola) autogestionária, feita pelo povo a partir de associações libertárias ou pelos próprios pais."

No curso de doutorado em Educação da Universidade Federal do Rio Grande do Sul, Juliane Soares Falcão Gavião apresentou a sua tese: "As crianças e suas memórias de infância: escola e homeschooling nas narrativas infantis" (2017). Trata-se de um estudo sobre a memória infantil que se propõe a analisar as narrativas das crianças, por meio de oficinas, nas quais a partir de diversos materiais como livros de literatura, filmes, brinquedos, "além das relíquias e dos registros fotográficos das próprias crianças", elas são elevadas à condição de depoentes privilegiadas do seu próprio contexto, portanto, de narradoras "do seu tempo, espaço e cultura", emergindo dessas narrativas "uma infância nãoescolar(izada), chamada Homeschooling ou Estudo em Casa". A autora discute, portanto, a prevalência decisiva deste tema na fala das crianças, em relação ao espaço escolar. Segundo ela, são "as narrativas infantis que permitiram delinear aquilo que denominamos neste estudo como um modo homeschooler de vida e suas implicações ao escolar.” (GAVIÃO, 2017, p. 9).

Marcelo Mazotti, no programa de pós-graduação em Direito da Universidade de São Paulo, defende uma tese de doutorado diferencial pelo seu aspecto comparativo: "O ativismo judicial no panorama do direito à educação: a intervenção do Poder Judiciário nas políticas públicas educacionais e seus efeitos práticos: estudo comparado entre o Brasil e os EUA" (2017). Nela, o autor se propõe a verificar aspectos que distanciam e aproximam o direito à educação no Brasil e nos Estados Unidos da América, com destaque para a distribuição de competências entre os entes federados, a regulamentação dos sistemas de ensino e o papel do poder judiciário na interpretação e efetivação de tal direito. 
Nesse sentido, o pesquisador analisa o direito à educação na Constituição Federal brasileira e aborda as razões pelas quais a Constituição Federal dos EUA não contempla expressamente esse direito, examinando a decisão da Suprema Corte quanto à inexistência de um direito fundamental implícito à educação no caso San Antonio Independent School District versus Rodriguez. Mazotti (2017) conclui que o Brasil apresenta uma centralização legislativa na União que acarreta uniformidade nacional e pouca autonomia dos demais entes (estados, municípios e o Distrito Federal), diferentemente dos EUA, onde a educação é considerada matéria de competência dos estados, o que gera maior autonomia, diversidade de sistemas de ensino e predominância de controle local. Entre outros tópicos comparativos, o autor aborda o homeschooling na jurisprudência de ambos os países, em especial, nos casos Prince versus Massachusetts e Wisconsin versus Yoder nos EUA e, no Brasil, na Repercussão Geral no RE 888.815 (STF) e no MS 7.407 no STJ.

Finalizando nossa revisão, citamos a tese de doutorado de Gabriele Nigra Salgado, do programa de pós-graduação em Educação da Universidade Federal de Santa Catarina, intitulada: "Educação 'alternativa': do discurso à imagem” (2018). Nela, a autora cria e discute um conceito de educação "alternativa”, investigando experiências de educação não institucionalizadas para entender as possibilidades de um aprendizado sem o ensino escolarizado, por meio do paradigma da desescolarização. Salgado (2018) apresenta a experiência do Coletivo Alecrim em fotografias, documentário, como uma experiência de educação "alternativa”, na qual "não existem relações de poder, ou currículo ou sala de aula, ou calendário escolar, ou avaliação etc.” A autora aborda as complexidades das relações no grupo, em busca de uma educação que assume uma perspectiva ética, abrindo-se para outra compreensão da relação pedagógica, a qual, sem afastar o convívio com o adulto (ao contrário), evita "o ponto de vista adultocêntrico e seus efeitos condicionantes" (p. 260). No entanto, a autora chama atenção para o fato de que não propõe que a análise das experiências seja comparada para superar uma forma de educação "tradicional" por outra "alternativa" e supostamente melhor, "mas sim apontar para as frestas da educação maior como potencialidades para a instalação de um devir (menor/revolucionário) que possibilite vivenciar a educação como invenção" (p. 261). 


\title{
CONSIDERAÇÕES FINAIS
}

Como se pode constatar, a produção acadêmica de dissertações e teses sobre a educação domiciliar tem aumentado a cada ano, não apenas em quantidade, mas também na ampliação de seu foco, ultrapassando os limites iniciais da discussão centrada na legislação e no direito à educação.

Cabe ressaltar que, nos anos de 2018 e 2019, certamente muitos outros trabalhos acadêmicos sobre essa temática foram produzidos em programas de pós-graduação, para além dos que constam dos quadros 1 e 2 , apresentados neste artigo, mas sua disponibilização nos bancos de dissertações e teses ocorre, por vezes, somente algum tempo depois. Soma-se a isso, o fato de que muitos trabalhos não constam sequer do repositório digital das próprias instituições onde são realizados, conforme pode ser constatado em pesquisa na web, reduzindo, notadamente, a sua divulgação. Dessa forma, a aparente diminuição da produção mais recente, é tão somente resultado de tais circunstâncias que impossibilitaram a inserção de trabalhos acadêmicos recém-defendidos em nossa revisão.

Nos dias atuais, diante de uma ameaça invisível que leva a todos a fazerem de suas casas um espaço de múltiplas possibilidades, a educação, mais do que nunca, tem que ser pesquisada em sua inserção nesse movimento. Além disso, diante da acusação de que as pesquisas das ciências humanas não são acessadas suficientemente para trazerem uma efetiva contribuição à sociedade, o momento vivido no primeiro semestre de 2020, com o isolamento social, mostrou, por meio de diferentes abordagens do assunto na mídia e nas redes sociais, que pesquisas como as apresentadas neste estudo foram espontaneamente buscadas pelas famílias para encontrar respostas à educação de seus filhos em um período sem precedentes, evidenciando a necessidade do tema ser cada vez mais explorado.

\section{REFERÊECIAS ${ }^{3}$}

\author{
ANDRADE, É. P. A educação familiar desescolarizada como um direito da \\ criança e do adolescente: relevância, limites e possibilidades na ampliação do \\ direito à educação. 2014. 552p. Tese (Doutorado em Educação) - Universidade \\ de São Paulo, São Paulo, 2014.
}

BARBOSA, L. M. R. Ensino em casa no Brasil: um desafio à escola? 2013. 350p. Tese (Doutorado em Educação) - Universidade de São Paulo, São Paulo, 2013.

3 Serão referenciados somente os trabalhos citados ao longo do texto. As informações sobre os trabalhos que fazem parte da revisão da literatura sobre a produção acadêmica constam dos quadros 1 e 2 . 
BECKER, C.; GRANDO, K. B.; HATTGE, M. D. Educação domiciliar, diferença e construção do conhecimento: contribuições para o debate. Práxis Educativa, Ponta Grossa, v. 15, n. e2014812, p. 1-12, abr. 2020. Disponível em: https://doi. org/10.5212/PraxEduc.v.15.14812.040 Acesso em: 8 abr. 2020.

BELMINO, M. C. de B. Ontologia gestáltica: um ensaio sobre a teoria da experiência em Paulo Goodman. 2016. 367p. Tese (Doutorado em Filosofia) Universidade Federal de Santa Catarina: Florianópolis, 2016.

CARVALHO, L. V. Ajuste estrutural do capital: alicerce da desconstrução da escola pública estatal. 2016. Tese (Doutorado em Educação) - Universidade Federal do Ceará, Fortaleza, 2016.

GARCIA, W. C. D. Direito à educação familiar. 2010. 264p. Tese (Doutorado em Direito) - Pontifícia Universidade Católica de São Paulo, São Paulo, 2010.

GAVIÃO, J. S. F. As crianças e suas memórias de infância: escola e homeschooling nas narrativas infantis. 2017.159p. Tese (Doutorado em Educação) - Universidade Federal do Rio Grande do Sul, Porto Alegre, 2017.

KLOH. F. F. P. De Canela a Brasília: nas vozes de um processo, a educação domiciliar chegou à Suprema Corte brasileira. 2020. 280p. Tese (Doutorado em Educação) - Universidade do Estado do Rio de Janeiro, Rio de Janeiro, 2020.

LYMAN, I. The homeschooling revolution. [S.:1.]: Bench Pr Intl, 2000.

MAZOTTI, M. O ativismo judicial no panorama do direito à educação: a intervenção do Poder Judiciário nas políticas públicas educacionais e seus efeitos práticos - estudo comparado entre o Brasil e os EUA. 2017. 246p. Tese (Doutorado em Direito) - Universidade de São Paulo: São Paulo, 2017.

PATIÑO, A. P. C. Intervenção estatal no exercício da autoridade familiar. 2012. 169p. Tese (Doutorado em Direito) - Universidade de São Paulo, São Paulo, 2012.

RIBEIRO, A. C. Homeschooling e controvérsias: da identidade à pluralidade - o drama da socialização. Práxis Educativa, Ponta Grossa, v. 15, n. e2014775, p. 1-22, mar. 2020. Disponível em: https://doi.org/10.5212/PraxEduc.v.15.14775.034. Acesso em: 8 maio 2020. 
RIO DE JANEIRO. Deliberação CEE n 376, de 23 de março de 2020. Orienta as Instituições integrantes do Sistema Estadual de Ensino do estado do Rio de Janeiro sobre o desenvolvimento das atividades escolares não presenciais, em caráter de excepcionalidade e temporalidade, enquanto permanecerem as medidas de isolamento previstas pelas autoridades estaduais na prevenção e combate ao Coronavírus - COVID-19. Diário Oficial do Estado do Rio de Janeiro, Rio de Janeiro, 25 mar. 2020.

SALGADO, G. N. Educação “alternativa”: do discurso à imagem. 2018. 297p. Tese (Doutorado) - Faculdade de Educação, Universidade Federal de Santa Catarina: Santa Catarina, 2018.

SANTOS, A. L. Educação domiciliar ou "lugar de criança é na escola"? Uma análise sobre a proposta de homeschooling no Brasil. 2019. 255p. Dissertação (Mestrado em Educação) - Universidade Federal do Rio de Janeiro, Rio de Janeiro, 2019.

SOUZA, M. F. Além da escola: reflexões teórico-metodológicas com base na análise de práticas educativas alternativas descobertas em áreas rurais da região de São Carlos-SP. 2016. 192p. Tese (Doutorado em Educação) - Universidade Estadual Paulista Júlio de Mesquita Filho, Araraquara, 2016.

VASCONCELOS, M. C. C. A casa e os seus mestres: a educação no Brasil de oitocentos. Rio de Janeiro: Gryphus, 2005.

VASCONCELOS, M. C. C. Educação na casa: perspectivas de desescolarização ou liberdade de escolha? Pro-Posições, Campinas, v. 28, n. 2, p. 122-140, dez. 2017. Disponível em: https://doi.org/10.1590/1980-6248-2015-0172 . Acesso em: 18 mar. 2020.

VASCONCELOS, M. C. C; BOTO, C. A educação domiciliar como alternativa a ser interrogada: problema e propostas. Práxis Educativa, Ponta Grossa, v. 1, n. 2014654, p. 1-21, dez. 2019. Disponível em: https://doi.org/10.5212/PraxEduc. v15.14654.019. Acesso em: 20 mar. 2020. 
VASCONCELOS, M. C. C; MORGADO, J. C. B. C. Desafios à escolarização obrigatória: a inserção do homeschooling na legislação educacional no Brasil e em Portugal. Revista Brasileira de Política e Administração da Educação, Recife, v. 30, n. 1, p. 203-230, dez. 2014. Disponível em: https://doi.org/10.21573/ vol36n12020.95824. Acesso em: 19 mar. 2020.

\section{Maria Celi Chaves Vasconcelos}

Pós-Doutora em Educação pela Universidade do Minho. Doutora em Educação pela Pontifícia Universidade Católica do Rio de Janeiro (PUC-Rio). Professora Titular da Universidade do Estado do Rio de Janeiro (UERJ), atuando no Programa de Pós-Graduação em Educação (Proped). Bolsista de Produtividade do Conselho Nacional de Desenvolvimento Científico e Tecnológico (CNPq). Bolsista do Programa Prociência (Uerj). Cientista do Nosso Estado/Fundação de Amparo à Pesquisa do Estado do Rio de Janeiro (Faperj). Presidente da Câmara Conjunta de Educação Profissional do Conselho Estadual de Educação do Rio de Janeiro (CEE/RJ). Pesquisadora na área de História da Educação e Políticas Educacionais, com ênfase na educação doméstica no Brasil oitocentista e criação/consolidação dos sistemas educacionais, além da educação na casa (homeschooling) e suas implicações na atualidade. Líder do Grupo de Pesquisa "História e memória das políticas educacionais no território fluminense" Uerj/CNPq. Autora de livros, capítulos e artigos científicos; e organizadora de coletâneas resultantes de trabalhos de pesquisa.E-mail: maria2.celi@gmail.com

\section{Fabiana Ferreira Pimentel Kloh}

Doutora pelo Programa de Pós Graduação em Educação da UERJ (20162019). Mestre em Educação pela Universidade Católica de Petrópolis (2014). Especialização lato sensu em Administração Escolar pela Universidade Cândido Mendes (2014). Licenciatura em História pela Universidade Católica de Petrópolis (2014). Especialização lato sensu pela UERJ na modalidade Residência Jurídica (2003), além de especialização em Educação Ambiental pela Universidade Católica de Petrópolis (2003). Graduada em Direito pela Universidade Católica de Petrópolis (2000). Professora da rede pública municipal de Petrópolis/RJ, concursada desde 1996. Professora de Direito Constitucional e Legislação do Ensino em cursos de atualização de profissionais do Direito e preparatórios para concursos públicos. Pesquisadora da Educação Domiciliar desde 2012. Orientadora Educacional do Colégio de Aplicação da Universidade Católica de Petrópolis. Membro titular da cadeira n. 38 na Academia Petropolitana de Educação. Professora na Universidade Católica de Petrópolis. Bolsista CAPES 2017-2019. E-mail: fabianapimentel@yahoo.com.br 